\title{
An Empirical Study on the Relationship between Psychological Contract and Job Satisfaction of the Cenozioc Employees
}

\author{
Li Ma ${ }^{1}$, Yunfei Shao ${ }^{1^{*}}$, Huinan $\mathrm{Li}^{2}$ \\ ${ }^{1}$ School of Management and Economics, University of Electronic Science and Technology, Chengdu, China \\ ${ }^{2}$ Department of Applied Psychology, University of Lingnan, Hongkong, China \\ Email: malicduestc@163.com, *shaoyf@uestc.edu.cn,1hn0249@outlook.com
}

How to cite this paper: Ma, L., Shao, Y.F. and Li, H.N. (2019) An Empirical Study on the Relationship between Psychological Contract and Job Satisfaction of the Cenozioc Employees. Open Journal of Social Sciences, 7, 105-120.

https://doi.org/10.4236/jss.2019.710010

Received: August 23, 2019

Accepted: October 14, 2019

Published: October 17, 2019

\begin{abstract}
How to manage the cenozioc employees to maximize the value of their human capital has always been a problem that plagues the practice world. However, the research on the relationship between the psychological contract and job satisfaction of the cenozioc employees is still scarce. This study examines the relationship between the psychological contract and job satisfaction of the cenozioc employees based on 142 valid data collected through structured questionnaire survey. The empirical results show that the cenozioc employees' job return satisfaction has positive correlation with the normative responsibility of organization, interpersonal responsibility of organization, developmental responsibility of organization, normative responsibility and developmental responsibility of employee, and has negative correlation with the interpersonal responsibility of employee. The cenozioc employees' job content satisfaction is positively correlated with the developmental responsibility of organization, normative responsibility and developmental responsibility of employee. The cenozioc employees' job relationship satisfaction is positively correlated with the interpersonal responsibility of organization and developmental responsibility of employee. The research conclusion has be in favor of the complete understanding of the theory of psychological contract and improvement of job satisfaction of the cenozioc employees from the perspective of psychological contract.
\end{abstract}

\section{Keywords}

Cenozioc Employees, Psychological Contract, Job Satisfaction

\section{Introduction}

The cenozoic employees are part of the employees who born in 1980-1999. They 
had received higher education, enjoyed good material conditions and were influenced by globalization and knowledge economy during their growth. The electronic technology also played an important role in their lives [1]. Unlike the previous generation of employees, job satisfaction is the core content of this group's work values [2]. Finding a suitable management style for the new generation employees to improve their job satisfaction, make them work better and reduce organizational conflicts is a urgent management problem that managers need to solve. As a psychological link that can express the two-way needs between the organization and the employees, the psychological contract becomes a good entry point for managers to improve their job satisfaction. For example, Katou [3] pointed out that if the organization can perform its responsibilities in the psychological contract well, the employee's job satisfaction and job performance can be improved. Therefore, clarifying the composition of the psychological contract of the new generation of employees and its relationship with job satisfaction will help managers to take targeted management measures from the perspective of psychological contract fulfillment to improve their job satisfaction and promote them to create value for the organization [4]. However, the current researches on the relationship between psychological contract and job satisfaction are mainly based on an industry, a certain enterprise or just completely randomly selected employees. For example, Zhang [5] believes that in small technical enterprises, the impact of psychological contract fulfillment on job satisfaction is significant. Liu et al. [6] believe that the effective implementation of psychological contract has a significant positive impact on the job satisfaction of nursing staff. Chen et al. [7] took Yonghui Organization as the case study object and constructed the theoretical framework of "Employee Incentive Fit-Psychological Empowerment-Job Satisfaction". Yuan et al. [8] by means of random sampling and typical survey concluded that psychological contract violation has a negative impact on employees' job satisfaction through data analysis. However, the relationship between psychological contract and job satisfaction of the new generation employees who are divided by intergenerational features is still lack of systematic and in-depth empirical research. In view of this, this paper focuses on the following issues:

1) What is the relationship between psychological contract and job satisfaction of the cenozoic employees with significantly different intergenerational characteristics?

2) How to improve the job satisfaction by enhancing the psychological contract of the cenozoic employees and finally improve organizational performance?

Based on the above research questions, this paper will use the method of empirical research, taking the cenozoic of employees as the research object, exploring the relationship between the psychological contract and job satisfaction of this group, perfecting the psychological contract and job satisfaction theory, put forward suggestions for improving the job satisfaction of cenozoic employees from the perspective of psychological contract fulfillment, and provide reference for managers to improve the management style and organizational performance 
of cenozoic employees.

\section{Theoretical Analysis and Research Hypothesis}

\subsection{Psychological Contract}

The concept of psychological contract was proposed by Argyris in 1960, emphasizing the implicit exchange relationship between organizations and employees. Although it has experienced nearly 60 years of development, there are still debates about its subject and content structure. In terms of perception subject, some scholars advocate "dual subjects", that is, psychological contract is the perception of employees and organizations on mutual responsibilities; while some scholars advocate "single subject", that means psychological contract is a perception system of employee's mutual responsibility and obligation [9]. The researches on the content structure of psychological contract can be divided into four categories: single-dimensional structure theory, two-dimensional structure theory, three-dimensional structure theory and other doctrines. The research of Chinese scholars pointed out that the three-dimensional structure theory which makes "interpersonal support and social connection between employers and employees" prominent can explain the psychological contract of Chinese employees more reasonably, and "organizational responsibility" and "employees' responsibility" both include normative, interpersonal and developmental dimensions [10].

In the definition of psychological contract, this study adopts the theory of "single subject" and "three-dimensional structure", that psychological contract is the perception of employees' mutual responsibilities. Employees' responsibility and organizational responsibility are divided into normative dimension, interpersonal dimension and development dimension. Among them, the normative responsibility emphasizes the basic, specific and clear responsibility of the employer and the employee; the interpersonal responsibility emphasizes the social connection, mutual trust and respect between the employer and the employee; the developmental responsibility emphasizes the responsibility of them for each other's success [10].

\subsection{Job Satisfaction}

At present, the research on job satisfaction is very rich, but there is no agreement on concept definition and dimension division. Feng [11] believes that job satisfaction is a complex system that includes cognitive evaluation and emotional feedback on work, and is closely related to work stress, physical and mental health and organizational culture. Zeng [12] divides job satisfaction into four dimensions: task self-satisfaction, salary and working environment satisfaction, promotion development satisfaction, and superior guidance satisfaction through empirical research methods. At the same time, he believes that the basic factors affecting job satisfaction are the work itself, compensation, work environment, interpersonal relationships, leadership style and promotion opportunities. Lan et 
al. [13] in the study of the relationship between job satisfaction and turnover intention of the cenozoic employees, divide job satisfaction into job itself satisfaction, salary satisfaction, personal development satisfaction, leadership satisfaction, colleagues satisfaction, satisfaction with working conditions, and considered that demographic characteristics such as age, personal income, education level, position and length of service can affect job satisfaction.

According to the existing research of comprehensive scholars, this paper believes that employee job satisfaction is the employees' subjective feelings about the work environment and the work itself, including job return satisfaction, job content satisfaction and job relationship satisfaction. Among them, job return satisfaction reflects the psychological feelings of non-material returns such as the employee's remuneration and other material rewards, as well as the promotion opportunities offered by the organization; the job content satisfaction reflects the psychological feelings of employee's competence in the work, the freshness and challenges of the work content, and the legitimacy of work content arrangements; job relationship satisfaction reflects the quality of relationships between employees and leaders and colleagues.

It can be seen from the above analysis that there is overlap or similarity between the content of the psychological contract and the content of job satisfaction, and the two concepts are closely related. At present, scholars have also confirmed that psychological contract have a certain relationship with job satisfaction. Based on the previous studies, this paper constructs a theoretical model of the relationship between psychological contract and job satisfaction of the cenozoic employees (see Figure 1).

\subsection{Research Hypothesis}

\subsubsection{The Relationship between the Cenozoic Employees' Psychological Contract and Job Return Satisfaction}

From the perspective of organizational responsibility, in the interaction between the organization and the employees, if the employees feel that the organization has set up a fair and reasonable salary and performance system, provide a comprehensive welfare and a safe and comfortable working environment, the employees will think that they have obtained the material return for their investment from the organization. Then they should have stable expectations and trust

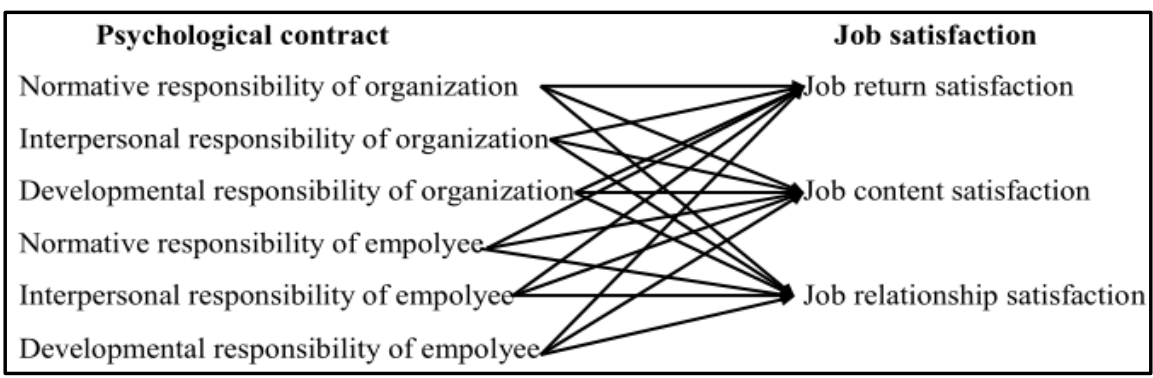

Figure 1. Theoretical model of the relationship between psychological contract and job satisfaction of cenozoic employees. 
for the organization; if the relationship between managers and employees is democratic, the organization will able to understand the employees' opinions and suggestions and adjusts according to the actual situation, and then can improve the job return satisfaction of employee; if the organization provides employees with smooth career development channels and targeted training, employees can gain opportunities and capabilities for improvement. They will feel support and care from the organization for their personal growth and will consider that their efforts will obtain sustained and long-term non-material returns. From the perspective of employee responsibility, employees create value for the organization by earnestly performing their duties, complying with the corporate system and behavioral norms, thereby obtaining the rewards they deserve and further securing other opportunities offered by the organization, while also stimulating the organization to fulfill its obligations; employees actively communicate with the superiors and subordinates, establish a harmonious interpersonal environment, and help to achieve fair and reasonable return on work; employees can make extra efforts to promote the development and success of the organization, and also enable to improve the material and non-material returns from the organization. Based on the above analysis, this paper proposes the following assumptions:

Hla: Normative responsibility of organization is positively correlated with job return satisfaction;

$H 1 b$ : Interpersonal responsibility of organization is positively correlated with job return satisfaction;

H1c. Developmental responsibility of organization is positively correlated with job return satisfaction;

$H 1$ d: Normative responsibility of employees is positively correlated with job return satisfaction;

H1 e: Interpersonal responsibility of employees is positively correlated with job return satisfaction;

H1f. Developmental responsibility of employees is positively correlated with job return satisfaction.

\subsubsection{The Relationship between the Cenozoic Employees' Psychological Contract and Job Content Satisfaction}

In terms of organizational responsibility, the organization's implementation of the normative psychological contract is also manifested in the strict implementation of the content of the labor contract, the involuntarily increase or decrease the work tasks of the employees, etc., which can effectively improve the satisfaction of the employees on the work content; When the organization fulfills the interpersonal psychological contract through actively promoting the communication between employees and their superiors, so that employees have the opportunity to reflect the problems at work and get corresponding solutions, which is conducive to improving the satisfaction of employees' work content. Appropriate training and promotion provided to employees will meet their own de- 
velopment requirements. The opportunity to use their abilities makes employees feel the meaning and value of their work, thus enhancing their satisfaction with the work content. In terms of employee responsibility, employees obey the work content arrangement, fulfill their tasks with due diligence, recognize the value and culture of the organization, all of those help to stimulate employees' sense of belonging and accomplishment, and then improve their recognition of the work content; employees actively communicate with their superiors to show their own opinions and suggestions on the setting of the work content that can be conducive to the superiors to understand the actual work situation of the employees and make timely adjustments to the work contents. At the same time, the positive communication between employees helps everyone to unite and improve efficiency, which is conducive to improving employees' satisfaction with the work content; employees actively participate in training to enrich themselves that can be more likely to win ideal positions and work content for themselves. Based on the above analysis, this paper proposes the following assumptions:

H2a: Normative responsibility of organization is positively correlated with job content satisfaction;

$H 2 b$ : Interpersonal responsibility of organization is positively correlated with job content satisfaction;

H2c. Developmental responsibility of organization is positively correlated with job content satisfaction;

$H 2 d$ : Normative responsibility of employees is positively correlated with job content satisfaction;

H2 e: Interpersonal responsibility of employees is positively correlated with job content satisfaction;

H2f. Developmental responsibility of employees is positively correlated with job content satisfaction.

\subsubsection{The Relationship between the Cenozoic Employees' Psychological Contract and Job Relationship Satisfaction}

From the perspective of organizational responsibility, a fair and equitable salary-performance system can avoid the unpleasantness that employees may have when comparing incomes, and help to ease employee relations and establish a harmonious and harmonious working environment. In addition, safe, comfortable and convenient working conditions also contribute to the creation of a good working atmosphere between employees, which helps to improve the satisfaction of working relationships; in the context of Chinese culture, leaders actively care about the work and living conditions of employees, Fair and open communication between the upper and lower levels can effectively improve the quality of the employee's work relationship; timely training opportunities and promotion also avoid unfair feelings when employees make horizontal comparisons, which is conducive to the formation of good relationships between employees. From the perspective of employee responsibility, employees perform their duties in the work and do not make mistakes in cooperation or work handover which can ef- 
fectively maintain the relationship between colleagues, thereby improving the satisfaction of employees' work relationships; employees can provide work support for colleagues, sharing information with the team and solving problems together are very helpful to maintain a good working relationship between colleagues; employees actively learn, take the initiative to make additional contributions to the development of the organization and maintain self-motivation. All these can convey positive energy to the organization and colleagues, and help to establish a good spirit of organization and organizational culture, thus creating a harmonious interpersonal atmosphere. Ultimately improve the job satisfaction relationship. Based on the above analysis, this paper proposes the following assumptions:

H3a: Normative responsibility of organization is positively correlated with job relationship satisfaction;

$H 3 b$ : Interpersonal responsibility of organization is positively correlated with job relationship satisfaction;

H3c. Developmental responsibility of organization is positively correlated with job relationship satisfaction;

$H 3 d$ : Normative responsibility of employees is positively correlated with job relationship satisfaction;

H3e: Interpersonal responsibility of employees is positively correlated with job relationship satisfaction;

H3f. Developmental responsibility of employees is positively correlated with job relationship satisfaction.

\section{Research Design}

\subsection{Sample Selection and Data Collection}

The data collection objects of this research are mainly employees engaged in knowledge activities in the fields of $\mathrm{R} \& \mathrm{D}$, high-end manufacturing, education, and administrative management services. The samples are mainly from Guangdong, Qinghai and Sichuan. After a three-month survey, a total of 200 electronic questionnaires and paper questionnaires were issued, and 173 questionnaires were finally collected. After removing the questionnaire that seriously lack of information and those does not meet the definition of the cenozoic employees, 142 valid questionnaires were obtained. The effective questionnaire recovery rate was $82.1 \%$. Among them, males accounted for $46.15 \%$, undergraduate and above accounted for $86.71 \%$, and working in one year or above accounted for $35.66 \%$. $37.06 \%$ of the subjects were from private enterprises, and $25.87 \%$ of the subjects were from state-owned enterprises and institutions. $14.69 \%$ of the respondents were from foreign or joint ventures, and $4.2 \%$ of the subjects were from government agencies.

\subsection{Variable Measurement}

In order to obtain effective scale, this study firstly, references some mature scale 
with high reliability and validity and taking full account of the characteristics of the cenozoic employees, secondly, carried out a pre-survey, then the measurement items were corrected according to the randomly selected 20 cenozoic employees' test feedback and exploratory factor analysis [10] [14]. Finally, the psychological contract scale is determined as 24 items, of which the three dimensions of organizational responsibility and employee responsibility are measured by four items. The employee job satisfaction scale was determined on the basis of the Minnesota Short Satisfaction Scaleas 12 items, each of which was measured with 4 items [15]. The scales are all based on the Likert 5 score, and the " $1-5$ " scores represent "completely non-conformity" to "fully match". The research variables and measurement indicators are shown in Table 1.

\subsection{Sample Reliability and Validity Test}

This study performed a Cronbach's $\alpha$ reliability test on the sample. The Cronbach's $\alpha$ coefficient for each dimension of all variables is greater than 0.7 (see Table 1), and the scale has higher reliability. In the validity test, first of all, the scale items are corrected on the basis of the maturity scale and pre-study, so they have high content validity. Secondly, the results of data analysis show that the KMO values of each dimension of psychological contract and job satisfaction are greater than 0.9 , and the $\chi^{2}$ value of Bartlett Spherical Test is significant at the level of sig value of 0.00 , The lowest value of the normalized factor load between its corresponding factors is greater than 0.5 (see Table 1), indicating that the construct of this study has good polymerization validity.

\section{The Verification of Research Hypotheses}

\subsection{Descriptive Statistics}

Table 2 gives the mean, standard deviation and correlation coefficient of the main variables of this study. The correlation coefficient of each variable is in line with the research needs.

\subsection{Hypothesis Testing}

Before performing regression analysis, it is necessary to test all three problems for all regression models. According to the questionnaire data, the VIF values of all model variables are lower than 10 , indicating that the model does not have serious multi-collinearity problem; the DW value of each regression model is between 1.5 and 2.5, means that the sequence-related problems do not exist; The scatter plot of the residual term of the regression model is a disorderly random distribution, indicating that the heteroscedasticity problem does not exist. Therefore, the regression analysis of the psychological contract and job satisfaction of the cenozoic employees can be carried out. The analysis results are shown in Table 3.

From the F values of Model 1 to Model 6, it can be seen that all six models are significant. The relationship between the five control variables of gender, age, 
Table 1. Variables and measurement indicators.

\begin{tabular}{|c|c|c|c|c|}
\hline Variable & Variable dimension & Measurement item & Factor Load & Cronbach's $\alpha$ \\
\hline \multirow{24}{*}{$\begin{array}{l}\text { Psychological } \\
\text { contract }\end{array}$} & \multirow{4}{*}{$\begin{array}{l}\text { Normative } \\
\text { responsibility } \\
\text { of organiztion }\end{array}$} & Organization can provide employees with comprehensive benefits & 0.842 & 0.915 \\
\hline & & $\begin{array}{l}\text { Organization can provide employees with } \\
\text { reasonable wages and pay on time }\end{array}$ & 0.871 & \\
\hline & & $\begin{array}{l}\text { Organization Provides employees with } \\
\text { a safe and comfortable working environment }\end{array}$ & 0.716 & \\
\hline & & Organization can provide employees with stable job security & 0.826 & \\
\hline & \multirow{4}{*}{$\begin{array}{l}\text { Interpersonal } \\
\text { responsibility } \\
\text { of organiztion }\end{array}$} & Organization cares about the work and living conditions of employees & 0.813 & 0.925 \\
\hline & & Organization provides timely work and life support for employees & 0.764 & \\
\hline & & Open and honest communication between the manager and employee & 0.796 & \\
\hline & & Organization treats all employees equally & 0.794 & \\
\hline & \multirow{4}{*}{$\begin{array}{l}\text { Developmental } \\
\text { responsibility } \\
\text { of organization }\end{array}$} & $\begin{array}{l}\text { Organization can provide employees with } \\
\text { opportunities for career advancement }\end{array}$ & 0.680 & 0.932 \\
\hline & & Work content can bring employee a sense of accomplishment & 0.771 & \\
\hline & & $\begin{array}{l}\text { Organization provides employees with training } \\
\text { opportunities to meet their development needs }\end{array}$ & 0.777 & \\
\hline & & Organization provides opportunities for employee career development & 0.771 & \\
\hline & \multirow{4}{*}{$\begin{array}{l}\text { Normative } \\
\text { responsibility } \\
\text { of employee }\end{array}$} & I finish job with good quality and quantity & 0.597 & 0.934 \\
\hline & & I am loyal to the organization & 0.748 & \\
\hline & & I maintain the external image of the organization & 0.781 & \\
\hline & & $\begin{array}{l}\text { I can obey the position exchanged } \\
\text { by the organization for the job arrangement }\end{array}$ & 0.798 & \\
\hline & \multirow{4}{*}{$\begin{array}{l}\text { Interpersonal } \\
\text { responsibility } \\
\text { of employee }\end{array}$} & I can provide support and help for colleagues & 0.783 & 0.946 \\
\hline & & I share information in the work team and solve problems together & 0.700 & \\
\hline & & I can cooperate with colleagues to complete work arrangements & 0.758 & \\
\hline & & I can maintain good working relationship with colleagues & 0.657 & \\
\hline & \multirow{4}{*}{$\begin{array}{c}\text { Developmental } \\
\text { responsibility } \\
\text { of employee }\end{array}$} & I can accept overtime work when necessary & 0.706 & 0.911 \\
\hline & & $\begin{array}{l}\text { I can take the initiative to make reasonable } \\
\text { Suggestions for the development of the organization }\end{array}$ & 0.691 & \\
\hline & & I am active learning to adapt to organizational development & 0.831 & \\
\hline & & I cherish the training opportunities offered by the organization & 0.679 & \\
\hline \multirow{12}{*}{ Job satisfaction } & \multirow{4}{*}{$\begin{array}{l}\text { Job return } \\
\text { satisfaction }\end{array}$} & The organization's compensation system is fair and reasonable & 0.574 & 0.882 \\
\hline & & I am satisfied with the overtime pay & 0.898 & \\
\hline & & My current work can give me the opportunity to advance & 0.595 & \\
\hline & & I Can get training opportunities that meet my development needs & 0.676 & \\
\hline & \multirow{4}{*}{$\begin{array}{l}\text { Job content } \\
\text { satisfaction }\end{array}$} & My current work is challenging and meaningful & 0.817 & 0.915 \\
\hline & & The work is ability to apply my knowledge and skills to my work & 0.846 & \\
\hline & & I can learn something new at work. & 0.799 & \\
\hline & & I have full autonomy and control in the work & 0.530 & \\
\hline & \multirow{4}{*}{$\begin{array}{l}\text { Job relationship } \\
\text { satisfaction }\end{array}$} & I get along well with my colleagues at work & 0.818 & 0.900 \\
\hline & & My superiors often give me guidance and help in my work & 0.790 & \\
\hline & & I am satisfied with the way my superiors treat me & 0.790 & \\
\hline & & I will be praised when I have a good job performance & 0.696 & \\
\hline
\end{tabular}


Table 2. Variable descriptive statistics and correlation coefficients.

\begin{tabular}{|c|c|c|c|c|c|c|c|c|c|}
\hline Variable & 1 & 2 & 3 & 4 & 5 & 6 & 7 & 8 & 9 \\
\hline 1 & 1 & & & & & & & & \\
\hline 2 & $0.607^{* * *}$ & 1 & & & & & & & \\
\hline 3 & $0.671^{* * *}$ & $0.794^{* * *}$ & 1 & & & & & & \\
\hline 4 & $0.765^{\star * *}$ & $0.606^{\star * *}$ & $0.611^{* * *}$ & 1 & & & & & \\
\hline 5 & $0.715^{* * *}$ & $0.535^{* * *}$ & $0.546^{* * *}$ & $0.860^{* * *}$ & 1 & & & & \\
\hline 6 & $0.736^{* * *}$ & $0.625^{* * *}$ & $0.598^{\star * *}$ & $0.808^{* * *}$ & $0.852^{* * *}$ & 1 & & & \\
\hline 7 & $0.575^{* * *}$ & $0.726^{* * *}$ & $0.809^{* * *}$ & $0.630^{* * *}$ & $0.500^{* * *}$ & $0.595^{* * *}$ & 1 & & \\
\hline 8 & $0.596^{* * *}$ & $0.650^{* * *}$ & $0.773^{* * *}$ & $0.650^{* * *}$ & $0.578^{* * *}$ & $0.661^{* * *}$ & $0.772^{* * *}$ & 1 & \\
\hline 9 & $0.708^{\star * *}$ & $0.744^{\star \star \star}$ & $0.700^{* * *}$ & $0.754^{* * *}$ & $0.746^{* * *}$ & $0.821^{* * *}$ & $0.719^{* * *}$ & $0.754^{\star * *}$ & 1 \\
\hline Mean & 3.89 & 3.35 & 3.46 & 3.91 & 4.02 & 3.88 & 3.28 & 3.49 & 3.73 \\
\hline Standard deviation & 0.949 & 0.912 & 0.890 & 0.849 & 0.841 & 0.862 & 0.925 & 0.943 & 0.838 \\
\hline
\end{tabular}

PS: 1.Normative responsibility of organization; 2.Interpersonal responsibility of organization; 3. Developmental responsibility of organization; 4 . Normative responsibility of employee; 5 . Interpersonal responsibility of employee; 6 . Developmental responsibility of employee; 7. Job return satisfaction; 8. Job content satisfaction 9. Job relationship satisfaction. ${ }^{*}$ means $\mathrm{P}<0.1,{ }^{* *}$ means $\mathrm{P}<0.05$, ${ }^{* *}$ means $\mathrm{P}<0.01$, two-tailed test, applicable to the table below.

Table 3. Hierarchical regression analysis of job satisfaction of cenozoic employees' psychological contract.

\begin{tabular}{|c|c|c|c|c|c|c|}
\hline \multirow{2}{*}{ Variable } & \multicolumn{2}{|c|}{ Job return satisfaction } & \multicolumn{2}{|c|}{ Job content satisfaction } & \multicolumn{2}{|c|}{ Job relationship satisfaction } \\
\hline & Model1 & Model 2 & Model 3 & Model 4 & Model 5 & Model 6 \\
\hline Gender & -0.18 & -0.11 & 0.008 & 0.009 & 0.034 & 0.005 \\
\hline Age & -0.94 & -0.037 & -0.042 & -0.019 & 0.097 & 0.034 \\
\hline Education level & 0.198 & 0.048 & 0.154 & 0.029 & 0.003 & -0.062 \\
\hline Working years & -0.007 & -0.029 & -0.018 & -0.022 & -0.168 & -0.136 \\
\hline Organizational nature & 0.011 & 0.003 & 0.102 & 0.098 & 0.075 & 0.067 \\
\hline Normative responsibility of organization & & -0.117 & & -0.133 & & 0.045 \\
\hline Interpersonal responsibility of organization & & $0.137^{*}$ & & -0.053 & & $0.281^{\star * *}$ \\
\hline Developmental responsibility of organization & & $0.580^{* * *}$ & & $0.615^{* * *}$ & & 0.133 \\
\hline Normative responsibility of organization & & $0.354^{* * *}$ & & $0.232^{\star \star}$ & & 0.059 \\
\hline Interpersonal responsibility of organization & & $-0.270^{* *}$ & & -0.124 & & 0.126 \\
\hline Developmental responsibility of organization & & $0.196^{*}$ & & $0.344^{* *}$ & & $0.372^{\star * *}$ \\
\hline $\operatorname{Adj} R^{2}$ & 0.018 & 0.700 & 0.004 & 0.660 & -0.013 & 0.776 \\
\hline $\mathrm{R}^{2}$ & 0.053 & 0.723 & 0.039 & 0.686 & 0.022 & 0.794 \\
\hline F value & $1.513^{\star * *}$ & $30.866^{\star * *}$ & $1.099^{* * *}$ & $25.829^{* * *}$ & $0.625^{\star * *}$ & $45.527^{\star \star *}$ \\
\hline
\end{tabular}

education level, working years and organizational nature and job satisfaction are not significant. On the basis of these five control variables, the six dimensions of the psychological contract are used as the independent variables to enter the regression equation using the input method to generate the model 2, the model 4 and the model 6 . It is found that the different dimension of the psychological 
contract has different influences on three dimensions of job satisfaction. In Model 2, in addition to the normative responsibility of organization, the remaining five dimensions of the psychological contract have a significant impact on job satisfaction, and the interpretation strength reaches $70 \%$, assuming that H1b, H1c, H1d, and H1f are supported. The data in Model 4 shows that the developmental responsibility of organization, the normative responsibility of employee and the developmental responsibility of employee have a significant impact on the work content satisfaction, and the interpretation strength reaches $66 \%$, assuming that $\mathrm{H} 2 \mathrm{~b}, \mathrm{H} 2 \mathrm{~d}$, and $\mathrm{H} 2 \mathrm{e}$ are supported; It can be seen that the interpersonal responsibility of organization and the development responsibility of employee have a significant impact on the job relationship satisfaction, and the interpretation strength reaches $77.6 \%$, assuming that $\mathrm{H} 3 \mathrm{c}$ and $\mathrm{H} 3 \mathrm{e}$ are supported.

\section{The Verification of Research Hypotheses}

\subsection{Research Conclusions}

Through empirical research, this paper tests the theoretical model and research hypothesis, clarifies the relationship between the psychological contract and job satisfaction of the cenozoic employees, and draws the following research conclusions.

1) The fulfillment of psychological contract has a significant impact on the improvement of job satisfaction of cenozoic employees, but the impact of various dimensions of psychological contract on job satisfaction is different. First of all, there is a strong and significant relationship between job satisfaction and developmental responsibility of organization and normative responsibility of employee, indicating that if the organization can provide challenging jobs, promotion and development opportunities for cenozoic employees, employees will think that they have paid fairly for their effort. At the same time, if the cenozoic employees believe that they have fulfilled their basic obligations to the organization and can exert their own value in the work, that will greatly improve their sense of work accomplishment, and the sense of work achievement is the most valued for the cenozoic employees. Secondly, the relationship between job satisfaction and interpersonal responsibility of organization, developmental responsibility of employee and interpersonal responsibility of employee are all more significant. This shows that when the cenozoic employees evaluate the return on their work, they will also consider whether the organization can give support to the work, be treated fairly, and have a smooth communication channel, can actively learn and contribute to the development of the organization and the quality of interpersonal relationships with colleagues. However, it is necessary to pay special attention to the significant negative correlation between interpersonal responsibility of employee and job return satisfaction. This may be because that the most cenozoic employees are only child. They had gained more care from their parents and grandparents since childhood, and had a strong sense of 
self-centeredness. In addition, they are a generation that has grown up in the process of China's reform and opening up and Internet popularization, they tend advocating freedom, independence and individuality in personal values [16], which leads them to hope that they will get the attention and support form organizations and leaders to achieve themselves. And if they are required to actively provide their colleagues with support and help, sharing information, etc., they may feel that is an extra effort beyond basic work responsibilities and compensation. It will reduce their actual job return. Finally, the relationship between normative responsibility of organization and job return satisfaction is not significant. This shows that the treatment provided by the organization and the stability of the work environment have no effect on the satisfaction of the job returns of the cenozoic employees. This may be more concerned with the improvement of individual performance with the cenozoic employees, actively seeking transformation and development, and has a strong sense of awareness and action for innovative behavior and innovation activities [2].

2) Job content satisfaction depends more on whether the developmental responsibility of organization, normative responsibility and developmental responsibility of employee are fulfilled. First of all, job content satisfaction has a significant relationship with the developmental responsibility organization, and has a more significant relationship with the normative responsibility and developmental responsibility of employee. Explain the reason that the organization should provides targeted training for Cenozoic employees to improve their confidence and ability to complete their tasks. When employees feel that they are well qualified for their work and have opportunities for promotion and development, this will be very helpful in improving the employee's satisfaction with the work content. Of course, employees themselves can actively learn, make extra efforts for the development of the organization, and will receive more training and development opportunities to achieve a virtuous circle. Secondly, job content satisfaction is not directly related to the normative and interpersonal responsibility of organization and interpersonal responsibility of employee. This may be related to the internal motivation of the cenozoic employees' work values, which is mainly based on the premise of "self-realization". When evaluating the value of work content, they often pursue the satisfaction of work achievement based on satisfying their own internal needs [2], and generally do not conside the status of the organization's basic obligations and interpersonal relationships into the value judgment of the work content.

3) The satisfaction of the job relationship is mainly determined by the interpersonal responsibility of organization and the fulfillment of the developmental responsibility of employee, but it has nothing to do with the employee's interpersonal responsibility. The cenozoic employees have a strong sense of self-centeredness and outstanding personality. They are only willing to maintain basic work and cooperation with colleagues. They are more concerned about equal communication channels and simple interpersonal relationship platforms [17]. This determines that the satisfaction of their work relationship is mainly 
due to the organization's respect and concern for it, the opportunity to express their own ideas and all the efforts come from their own voluntary rather than power or human pressure.

\subsection{Theoretical Contribution and Practical Enlightenment}

\subsubsection{Theoretical Contribution}

Through empirical research, this paper has the following contributions to the psychological contract and job satisfaction theory: 1) This paper expands the application scope of psychological contract and job satisfaction theory. This paper takes the cenozoic of employees as the research object, and expands the application of the theory of the psychological contract and job satisfaction in the group divided by generational characteristics. 2) This paper clarifies the micro-relationship between the psychological contract and job satisfaction of the cenozoic of employees. In this paper, the psychological contract is set as the single subject of employees, the two-way perception of organizational responsibility and employees' responsibility, and the three dimensions of normative, developmental and interpersonal. Job satisfaction is divided into three dimensions that are job return, job content and job development. The relationship between the variables is verified one by one, and the research model is refined, which are conducive to deepening the understanding of the relationship between the psychological contract and job satisfaction of the cenozoic employees.

\subsubsection{Practice Enlightenment}

The research conclusions of this paper are inspiration for the organization to improve the job satisfaction of the cenozoic of employees: 1) The organization should pay special attention to the impact of the development of the organization development responsibility and employee development responsibility on the job satisfaction of the cenozoic employees. First of all, the job provided by the organization to the cenozoic employees should be consistent with the characteristics of this generation's desire for new things and strong sense of innovation. The content of the work should help them broaden their horizons, apply new knowledge and have certain challenges. Organizations can achieve this through measures such as scientific job design and systematic work rotation. Secondly, the organization can work with the cenozoic employees to design a career development plan for them, and design a systematic training system to improve their professional development capabilities. At the same time, it should be ensured that each position has a corresponding promotion channel to meet the strong demands of the cenozoic employees in personal progress and career development. Finally, build a learning type organization culture, guide the cenozoic employees to actively explore new knowledge, learn new skills, help organizations cope with environmental dynamics and technological changes, and improve their professional accomplishment. 2) The organization should pay attention to the fulfillment of the normative responsibility of the psychological contract to improve the job satisfaction of the cenozoic employees. The organi- 
zation should pay attention to the construction of corporate culture, and at the same time, carry out corporate culture infiltration activities to strengthen the recognition of the cenozoic employees on organizational culture and vision. Once they perceive their willingness and ability to perform their duties and loyalty to the organization, it will greatly stimulate their sense of value to the organization, thus improving job satisfaction. 3) The organization should pay special attention to the impact of the unique characteristics of the cenozoic employees on the job satisfaction. First of all, we should try to design a flat organizational structure, reduce the resistance of the cenozoic employees to the hierarchy of the bureaucracy and traditional authority, and provide them with opportunities for self-expression and equal communication. Secondly, the cenozoic employees have strong motivation for work, but they are weak in frustration and resistance. When facing difficulties and stress, they are easy to be emotional. So organizations should pay attention to their mental health by setting up a special mental health studio and necessary work support, give them psychological counseling in time. Finally, through the establishment of employee interest clubs, quality development and employee party activities, strengthen the mutual understanding of the Cenozoic employees, and guide them to share work information, unity and mutual support.

\subsection{Insufficient Research and Prospects}

The following deficiencies exist in this paper. In order to deepen and improve the follow-up research, scholars can do as follows: First, some hypotheses in the conceptual model of this study are not supported by empirical data. Author explains the reasons why the hypothesis is not established from the personality traits and work value dimensions of the cenozoic employees. However, the characteristics of the cenozoic employees are mostly derived from the subjective feelings and experience of the researchers. Because there is still no empirical test on these characteristics. It is lacks of persuasive to a certain extent that the author uses the characteristics of the cenozoic employees as the reason for hypothesis not supported. Subsequent research needs to strengthen the empirical test of the intergenerational characteristics of the cenozoic employees and its impation on the relationship between psychological contract and job satisfaction. Secondly, the cenozoic employees grow up in the period of great changes in China's economy, society, culture and values. Enterprises also face complex and ever-changing external environment and technological changes, which determines the relationship between the psychological contract and job satisfaction of the cenozoic employees, to be very complicated. This study does not reveal the internal mechanism and contingency factors of the psychological contract affecting job satisfaction of the cenozoic employees. Follow-up studies need to include mediation variables such as organizational identity and emotional support, as well as moderating variables such as personality traits and organizational culture. 


\section{Acknowledgements}

The authors gratefully acknowledge the funding received through the Sichuan Key Research Base of Philosophy and Social Science: Sichuan Center for Education Development Research of China West Normal University's CJF19010 research project, and they would also like to express their gratitude for the financial support received from the Chengdu Science and Technology Bureau's 2017-RK00-00432-ZF research project. Errors remain their own.

\section{Conflicts of Interest}

The authors declare no conflicts of interest regarding the publication of this paper.

\section{References}

[1] Wu, H.J. (2017) Study of the Relationship between Cenozoic Employee Psychological Contract and Employee Performance. Qingdao University of Science and Technology.

[2] Sun, J.L. (2019) Cenozioc, Mesozoic and Old Generation Employees' Demand Conflict and Resolution Strategies. Leadship Science, 2, 70-72.

[3] Katou, A.A. (2013) The Link between HR Practices, Psychological Contract Fulfillment, and Organizational Performance in Greece: An Economic Crisis Perspective. Journal of Industrial Engineering and Management, 2, 568-594. https://doi.org/10.3926/jiem.501

[4] Yu, G.Y. (2015) An Empirical Study on the Relationship between Psychological Contract and Turnover Intention of Cenozoic Employees. Jiangxi Social Science, 8, 198-202.

[5] Zhang, C.J. (2012) Psychological Contract Fulfillment Mediates the Relationship between Leaders and Subordinates, Job Satisfaction and Turnover Intention: An Empirical Study on 556 Employees in Small and Micro Technology Enterprises. Modern Management Science, 2, 41-44.

[6] Liu, X.J., Huang, M.L. and Guo, S.J. (2016) Application Status of Psychological Contract in Nursing Management. Chinese Nursing Management, 16, 285-288.

[7] Cheng, W., Zhang, Y. and Wu, X.Y. (2017) How Can Retail Enterprises Effectively Motivate Front-Line Employees: Based on the Case Study of Yonghui Supermarket. Human Resource Development of China, 7, 110-122.

[8] Yuan, L., Dai, B. and Zhang, L.L. (2014) Research on Influence of Psychological Contract Breach on Job Satisfaction Based on the Moderating Role of Group Identification. Soft Science, 8, 56-59.

[9] Li, H. (2015) Research on the Impact of Fulfillment of Psychological Contract to the Turnover Intention of the Cenozoic of Knowledge-Based Staff. Shandong University.

[10] Li, Y. and Guo, D.J. (2006) Research on the Structure and Internal Relationship of Psychological Contract of the Employee. The Study of Sociology, 5, 159-164.

[11] Gao, F. (2008) Research on Job Satisfaction of the Enterprises' Employees and It's Correlative Factors. Henan University.

[12] Zeng, B. (2010) Empirical Research on the Relationship between Psychological Contract, Job Satisfaction and Turnover Intention. Zhejiang Sci-Tech University. 
[13] Lan, Y.J. and Zhang, C.L. (2013) A Research on the Relationship between Job Satisfaction and Turnover Intention in the Cenozoic Staffs. Economic Management, 9, 81-88.

[14] Rousseau, D.M. (1990) New Hire Perceptions of Their Own and Their Employer's Obligations: A Study of Psychological Contracts. Journal of Organizational Behaviour, 11, 389-400. https://doi.org/10.1002/job.4030110506

[15] Feng, J. and Qing, Q.W. (2009) Job Satisfaction Research Review. Psychological Science, 4, 900-902.

[16] Zhang, G.L. and Zhou, J.F. (2015) Review on the Research of Definition and Characteristics of the Cenozoic of Employees. Journal of Wuhan University of Science and Technology (Social Science Edition), 4, 449-454.

[17] Zhu, G.H. (2018) Intergenerational Characteristics, Performance and Incentive Strategies of Post-1990 Employees. Leadship Science, 32, 57-58. 